\title{
Optimization assessment of the energy performance of a BIPV/T-PCM system using Genetic Algorithms
}

\author{
Ricardo Pereira, Laura Aelenei* \\ Energy Efficiency Unit of National Laboratory for Energy and Geology, Lisbon, Portugal, Estrada do Paço do Lumiar, 22, 1649-038, Lisboa, Portugal
}

\section{A R T I C L E I N F O}

\section{Article history:}

Received 19 July 2017

Received in revised form

21 June 2018

Accepted 30 June 2018

Available online 4 July 2018

\section{Keywords:}

Building integrated photovoltaic/thermal

Energy storage

Phase-change material

Thermal modelling

Genetic Algorithm

\begin{abstract}
A B S T R A C T
In this paper, a BIPV/T-PCM installed in an office building façade is investigated to approach the system efficiency optimization using Genetic Algorithm method. Based on an updated mathematical model, theoretical simulation has been conducted for BIPV/T-PCM in this case for the existing system set-up (geometry-air cavity width, ventilation, system layers). Furthermore, field testing for this case has also been performed to validate the model, and then the simulated and experimental results are compared and found in considerably good agreement. The overall energy efficiency of the system was evaluated for winter and summer condition adopting different utilization strategies and optimization variables have been identified. The thermal and electric efficiencies were calculated based on the optimization variables and the results shown that the system can achieve a maximum overall efficiency of $64 \%$ with winter configuration and $32 \%$ with summer configuration.
\end{abstract}

(c) 2018 Elsevier Ltd. All rights reserved.

\section{Introduction}

In the case of Building Integrated Photovoltaic systems (BIPV) according with some authors, only about $16 \%$ of the solar energy incident on a PV, is converted to electricity, the remaining, being absorbed and transformed into heat [1]. The component transformed into heat can cause overheating problems in the case of Photovoltaic panels (PV) integrated systems [2]. Elevated operating temperatures, on the other hand, reduce the solar energy conversion efficiency of photovoltaic module. By ventilation of the air cavity behind the PV module, the heat released in the conversion process from PV can be successfully recovered for indoor heating (BIPV/T), and/or by using Phase Change Materials (PCM) can be stored for leveling the temperature difference between indoor and outdoor and a rapid stabilization of PV modules temperature (BIPV/ T-PCM). In the framework of a project for integrated of PV systems in building's façade, a study on using BIPV with heat recovery (BIPV/T) and combination with storage element (BIPV/T-PCM) was developed having in mind to avoid PV overheating and improve the overall efficiency of the system through a combination of geometrical parameters and properties. The BIPV/T-PCM prototype was installed in the SolarXXI building façade [3,4]. A dynamic model of the thermal behavior of the system was developed and validated by Pereira $[4,5]$, considering different climatic conditions

\footnotetext{
* Corresponding author.

E-mail address: laura.aelenei@Ineg.pt (L. Aelenei).
}

and consequently utilization strategies (winter and summer). The overall energy efficiency of the system was calculated for winter and summer condition and different utilization strategies. The simulation results were optimized through Genetic Algorithms enabling to find the best combination between the ventilation (flow rate), dimensions of the air cavity and PCM layer and the latent heat capacity, with the objective of maximizing the overall energy efficiency of the system.

Researchers strive to improve the energy efficiency of this kind of systems, since some energy is lost in each of the conversion processes. Developing systems that include energy conversions more efficient can help to reduce energy consumption and the production of greenhouse gas emissions. Parameters such as solar radiation and airflow rate, wind velocity, orientation, location, exterior temperature, slope, and material proprieties are particularly important. The heat lost in the conversion process can be recover for heating purposes in different applications. As mentioned, elevated operating temperatures, reduce the solar energy conversion efficiency of photovoltaic module. The cooling of the solar cells and so improving electricity yield can be done with a fluid stream like air or water. There does seem to be a direct relation between the higher efficiencies obtained by the authors and the type of systems studied (facade, roof, air or water) (Fig. 1).

When integrated in the façade (Fig. 1), generally, the BIPV/T systems with water as working fluid, achieved higher overall efficiency $(47.5 \%-62.3 \%)$ than air systems $(20.9 \%-24.8 \%)$ although there are situations when the air system present highest values, as 